\title{
DỨcin
}

Technological University Dublin

ARROW@TU Dublin

Articles

Centre for Social and Educational Research

2011-10

\section{Who Benefits from Early Childcare Subsidy Design in Ireland?}

\author{
Bernie O'Donoghue Hynes \\ Technological University Dublin, bernie.odonoghue@tudublin.ie \\ Noirin Hayes \\ Technological University Dubin, noirin.hayes@tudublin.ie
}

Follow this and additional works at: https://arrow.tudublin.ie/cserart

Part of the Education Policy Commons, Inequality and Stratification Commons, Other Education Commons, Other Political Science Commons, Policy Design, Analysis, and Evaluation Commons, Politics and Social Change Commons, Public Administration Commons, Public Policy Commons, Social Control, Law, Crime, and Deviance Commons, Social Policy Commons, and the Social Welfare Commons

\section{Recommended Citation}

O'Donoghue Hynes, B., Hayes, N. (2011) Who benefits from early childcare subsidy design in Ireland? Journal of Poverty and Social Justice, vol. 19, no. 3, pp.277- 288. doi:10.1332/175982711X597017

This Article is brought to you for free and open access by the Centre for Social and Educational Research at ARROW@TU Dublin. It has been accepted for inclusion in Articles by an authorized administrator of ARROW@TU

Dublin. For more information, please contact

arrow.admin@tudublin.ie, aisling.coyne@tudublin.ie, gerard.connolly@tudublin.ie.

Funder: IRCHSS

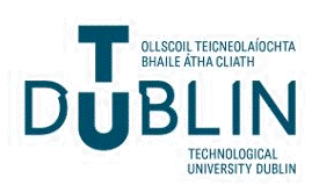




\title{
Who benefits from childcare policy design in Ireland?
}

\section{Bernie O’Donoghue Hynes and Noirin Hayes}

\begin{abstract}
The design of policy tools reveals underlying biases that are not easily identified in policy documents. A review of two early childhood education and care subsidies in Ireland aimed at different target populations exposes differential treatment of children, parents and service providers. It also demonstrates how in a split system 'early education' is prioritised over 'childcare'. The designs serve to reinforce stereotypes which enable the powerful and advantaged to accrue benefits while those perceived to be less deserving are burdened through the maldistribution of resources.
\end{abstract}

\section{Introduction}

Funding mechanisms can be designed as either supply or demand-side policy tools. The overall aim of supply-side funding mechanisms is to stimulate an expansion in the supply of and demand for services as this is believed to be in the best interests of target populations. In the area of early childhood education and care (ECEC), supply-side policy tools can take many forms including operational grants, payment of staff wages or grants for capital to enhance quality or purchase equipment. These tools are prevalent in social democratic states where strict regulation and adequate funding are key design features supporting goals to enhance the supply of and access to quality affordable ECEC services (OECD 2006). In more liberal economies such as the US, Canada, the United Kingdom and Ireland there is a tendency to rely more on demand-side funding mechanisms such as subsidies, cash benefits or vouchers where funding is paid following a demand for the provision services (OECD 2006). These policy tools do not construct the provision of ECEC as a benefit of social citizenship provided by the government but rather as “a service-customer transaction” (Rigby, Tarrant et al. 2007: 103). There is a reliance on market solutions to tackle the 'childcare problem' resulting in a 'non-interventionist' approach (Milner 2010) that enables policy makers to remain distanced from the problem and, in the case of Ireland, defers the articulation of a clear rationale for investment in ECEC development. 
In states where there is a commitment to developing affordable, accessible and high quality ECEC service, policy tools tend to incorporate features to inform parents that the actions advocated by the State are in their best interest. In addition to the obvious financial incentives, tools are developed to share power and give voice to target populations (Schneider and Ingram 2005). Features of design often include outreach, capacity building, and educational and informational supports to ensure target populations have the capacity to make informed decisions. Through these actions the State makes efforts to align the value systems of the State and target populations (Schneider and Ingram 1990). These design features are evident within the OECD region and include: capping the fee portion paid by parents; investment in sectoral training in quality evaluation; establishment of parent councils and parent-pedagogue/owner co-ordinating committees; and stipulating minimum qualification for staff (OECD 2006). Once again, these positive features are more prevalent amongst the social democratic states and are applied using a 'universalist' rather than a 'targeted' approach. However, Schneider and Ingram’s (1997; 2005) work in the US indicates that when these policy tool designs are used in neo-liberal states they tend to be reserved for more 'advantaged' target groups while less deserving groups are exposed to policy tool designs that ensure the divisions in society are perpetuated rather than challenged, a finding that is supported by this review of ECEC subsidy design in Ireland.

Many neo-liberal states within the OECD are also associated with a 'split system' (European Commission 2009) in which 'early education' services, with professional qualified staff, for over-threes are supported by the state in order to enhance and develop the 'human capital' of children (Heckman and Masterov 2007). In contrast access to subsidised services for the under-threes is frequently aimed at facilitating the employment of targeted parents, and funding supports are limited to early childhood 'care' with no identifiable 'educational' aim. Other parents look to the market to purchase services so those that can afford it, the more advantaged families, can avail of the higher quality ECEC type services for their children from a young age. 


\section{Why social constructions of policy target populations matter}

A focus on how target populations are 'constructed' within the selection and design of policy tools is important because path-dependency theory predicts that these constructions invariably become institutionalised (Pierson 2000). Where constructions are based on negative stereotypes, serious implications for how benefits and burdens are distributed emerge as "material resources and social status are consistently distributed through institutions to deepen the cleavages between advantaged and other target populations" (Schneider and Ingram 2005: 19). Powerful messages about "who matters in our society” are reinforced while the "institutionalisation of bias has enormous influence upon citizenship roles, group mobilization and civic participation" (ibid). The 'stereotype and social identity threat' has also been determined as the key factor in undermining performance of the disadvantaged and minorities, particularly in relation to academic achievement (Steele, Spencer et al. 2002; Carr and Steele 2009).

This interpretive research study aims to look beyond what the State 'says' in its policy documents to reveal whose values and interests are being served through the design of policy tools to implement policy (Yanow 2007). Through a comparative review of two ECEC subsidies aimed at different target groups, a range of design tactics are revealed supporting the general findings of policy tool design researchers in other neo-liberal states (Schneider and Sidney 2009). Literature developed by the State and feedback from other stakeholders, gathered in part through interviews with parents and community childcare providers (CCPs) ${ }^{\mathrm{i}}$, is reviewed in order make visible the often deeply held values and assumptions about how target populations behave and should be treated.

\section{Target populations}

In order to carry out a review of the design elements of the two ECEC subsidies in Ireland, the research uses a framework that identifies four different types of target population. The groups are categorised based on a perception of their level of power, particularly in relation to elected politicians, and how positively or negatively the electorate construct the target groups (Schneider and Ingram, 1997). The four categories are:

Formatted: Font: Times New Roman, 12 pt

Formatted: Line spacing: 1.5 lines 
| the advantaged, who are politically powerful and are positively constructed as deserving; contenders, who are perceived to be powerful but are negatively constructed as being somehow undeserving; deviants, who are deemed to be undeserving, while having little or no power; and finally dependants, who have little power to influence policy design or define problems but the construction of these groups as deserving is positive, although not complimentary (Ingram and Smith 1993),

While a focus on the dimensions of power and influence and levels of deservedness may appear limited and social constructions can vary between welfare regimes and states in relation to the different target groups such as children (James and Prout 1997), family (Hantrais 2004) and business (Whitley 1991), the overall classifications are useful as they enable the research to reveal biases contributing to an unequal distribution of resources that needs to be challenged.

\section{Subsidy Design for Different Target Groups}

The Community Childcare Subvention Scheme (CCSS) is a 'targeted' subsidy designed as a social inclusion measure that aims to benefit welfare recipients. The universal Free PreSchool Year in Early Childhood Care and Education (FPSY) is an early education subsidy offering a limited number of free preschool hours to all children, although this type of scheme is typically not accessed by the most disadvantaged (Sylva et al, 2004; OECD,2006).

When looking at how the CCSS compares with the new FPSY scheme, differences emerge in how parents, children and service providers are treated.

The literature of the Office of the Minister for Children and Youth Affairs (OMCYA), produced to provide basic information on the CCSS, appears to reveal three target groups for this social inclusion scheme (2008): children who are the end users of the services provided; the qualifying parents who are incentivised to place their children in community childcare services by receiving a reduced rate fee; and the Community Childcare Providers (CCPs) who are financially incentivised to provide services in 'areas of market failure'. While the FPSY also targets children, parents and service providers, the construction of these target
Deleted: In order to carry out a review of the design elements of the two ECEC subsidies in Ireland, the research uses a framework that identifies four

different types of target populations based on: (i) the perception of their level of power, particularly in relation to elected politicians; and (ii) how positively or negatively the electorate construct the target groups to be (Schneider and Ingram 1997). The four categories are:

Deleted: (Ingram and Smith, 1993)
Deleted: While a focus on the dimensions of power and influence and levels of deservedness is limited and there are some deviations in how the various target populations are

perceived in Ireland relative to the

US, because of cultural and

political structural reasons, the overall classifications are useful

as it enables the research to reveal biases that contribute to an

unequal distribution of resources that need to be challenged
Deleted: The Community Childcare Subvention Scheme (CCSS), is a subsidy designed as a social inclusion measure that aims to benefit welfare recipients, while the universal Free Pre-

School Year in Early Childhood Care and Education (FPSY), is an early education subsidy offering a limited number of free pre-school hours to all children, a scheme typically found to be accessed by more 'advantaged' groups (Sylva, Melhuish et al. 2004; OECD

2006). 
groups as being more powerful and deserving results in subtle difference in design that ensure the stereotypes are perpetuated in Ireland.

\section{Children as invisible or dependent}

The CCSS is an incentive tool (Schneider and Ingram 1990) designed to give financial support to CCPs to "provide quality childcare services at reduced rates to disadvantaged parents" (OMCYA 2008). CCPs are paid a per-capita subsidy that is deducted from the childcare fee that parents have to pay, to assist those "who are in receipt of social welfare payments" or those with "an underlying entitlement to social welfare payment" participating in approved state supported education, training or work experience programmes (OMCYA, 2008),

However, while the children of qualifying parents are a clear target as they are end users of the service, there is no rationale outlined in the scheme's literature to explain why they should participate in ECEC services or what type of experience they can expect to have. They are 'invisible' outside the word 'childcare' being included in the name of the scheme. Within the design eligibility for access is based solely on the welfare status of parents while the needs of children are not addressed at all. As CCPs are subsidised for only part of the cost of each child's place under the CCSS, each of the CCPs interviewed had a varied 'funding mix', accessing additional funding sources from different state departments as well as charging parents fees. They relied on this additional funding to ensure they were not limited to childcare but could deliver on the educational element too, which they saw as critical to the target group of children they served.

This contrasts with the treatment of children under the FPSY where eligibility focuses on the child as "the ECCE [FPSY] is open to all children aged between 3 years 3 months and 4 years 6 months on 1 September each year” (OMCYA 2009a). The FPSY moves beyond outlining details on the mechanics of how the scheme works (which is the focus of the CCSS literature), to providing information on why the scheme can benefit children. The child remains a dependant in this scenario but the aims and objectives in terms of the behaviour of children are clear: 
Participation in a pre-school programme provides children with their first formal experience of early learning, the starting-point of their educational and social development outside the home. Children who avail of pre-school are more likely to be ready for school and a formal learning and social environment. (OMCYA 2009a)

Although the OMCYA are offering parents a limited number of free part-time pre-school hours not all parents avail of the scheme as they have the option of sending children to school once they reach the age of four. This can be a more attractive option for some working parents as schools offer longer hours thus reducing the need for paid childcare. The CCPs interviewed during this research pointed out that parents were not always aware of the specific benefits of ECEC for their children so decisions were made by parents with an 'information deficit' that the State had not addressed.

The CCPs also identified an element of competition emerging for these four year old children in response to state funding reductions. They reported that some local schools were actively encouraging parents to start their children in school when aged four, although not required to start school until aged six, as schools struggle to maintain funding levels. The lack of policy co-ordination between the various funding streams has created a situation that negatively impacts upon children as research suggests that children, particularly those from disadvantaged backgrounds, benefit from participation in quality ECEC services (SirajBlatchford, Sylva et al. 2007) yet these are the children most likely to miss out on the preschool experience (Sylva, Melhuish et al. 2004). Children as dependents in this scenario have no 'right' to access services so are reliant on the capacities of parents to do what is in best interests of the child.

\section{Dependent and advantaged parents}

When looking at the construction of parents clear differences emerge in how they are treated. The literature supplied to parents by the OMCYA about the FPSY clearly identifies the rationale for the scheme and reiterates the benefits of participation for their children. This is in line with expectations that the types of policy tools normally reserved for more powerful and deserving groups tend to "emphasize capacity building, inducements, and techniques that enable the target population to learn about the results of its behaviour and take appropriate action on a voluntary basis” (Schneider and Ingram 1993: 339). 
In an attempt to stimulate the demand for the FPSY, the OMCYA engages in outreach activities as it writes directly to all parents in the State with children that fall within the qualifying age criteria to inform them of the scheme but also to enlist them as 'problem solvers'. Parents are encouraged to actively recruit their current service providers into the scheme if not already participating (OMCYA, 2009a), thus increasing the supply:

If your child is already attending a pre-school service ... you can ask the service provider if they plan to participate in the scheme (OMCYA 2009a).

This contrasts with how parents are 'managed' from a distance under the CCSS. The CCP managers interviewed revealed most parents heard about the CCSS through networking with other parents. So 'word-of-mouth' is relied upon as the principal method of enrolment. CCPs felt there was a pragmatic reason for the State's reluctance to engage in extensive outreach efforts. The subsidy schemes managed by the OMCYA have 'closed' budgets (Purcal and Fisher 2006) which limit participant numbers, resulting in a need to manage demand. With the increase in the numbers of people in receipt of welfare since the on-set of the recession in 2008, the CCPs could not cater for the numbers of qualifying children. In the case of the FPSY, the numbers of children are calculated by the department in advance and to date adequate funding has been provided, despite massive budget cuts elsewhere. This trend, established by a Fianna Fail government, seems set to continue under the replacement Fine Gael/Labour coalition government as their Government for National Recovery 2011-2016 outlines a firm commitment to "maintain the free pre-school year in Early Childhood Care and Education to promote the best outcomes for children and families” yet investment in “targeted early childhood education programme for disadvantaged children” will continue only if “resources allow” (Government of Ireland 2011: 39).

Another distinguishing feature of the CCSS is that parents are required to "present themselves to the agency to receive benefits” (Schneider and Ingram, 1993: 339). When parents were asked how they felt about handing over personal and financial details to local CCPs to receive the CCSS subsidy rate, they overwhelmingly accepted the process (O’Donoghue-Hynes and Hayes, 2011). A large portion of questionnaire respondents were single parents who were probably quite familiar with the ritual of 'presenting themselves' and, as Soss revealed in his research, can feel the need to be deferential to workers and fit into the image of the 'deserving poor' (1999). Perhaps then, as predicted by Schneider and 
Ingram, negative stereotypes are being reinforced inadvertently by target groups themselves and over time they come to accept that "the maldistribution of resources is simply the way things are or that the entitled are truly more deserving than they are” (2005: 8).

The welfare dependent target groups are further 'trapped' as CCSS financial subsidy is withdrawn over a period if their employment or welfare status changes. As a result, the majority of parents questioned revealed they would consider the financial implications on their overall family budget before taking up employment.

Overall the CCSS typifies a subsidy design aimed at dependent target groups in which a key feature is “labelling and stigmatizing recipients” (Schneider and Ingram 1993: 339).

\section{All the community services participating in the research were located in designated areas of} disadvantage however, following the introduction of the CCSS half of the services saw children of local working and married parents take children out as they no longer qualified and they were replaced with children of welfare recipients, that in many cases were single parents.

, CCPs were concerned that services would become 'ghettoised' but also that the lack of a social mix amongst service users reduced opportunities for an integrated educational approach in which diversity is recognised and respected (Clancy 1995). This is particularly relevant as research has shown that childcare choices that segregate "generate and maintain class divisions and work to reproduce differential educational opportunities” (Vincent and Ball 2006: 63).

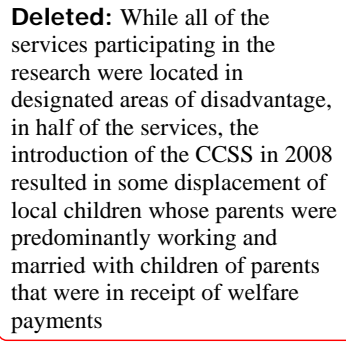
research were located in designated areas of disadvantage, in half of the services, the introduction of the CCSS in 2008 resulted in some displacement of local children whose parents were predominantly working and married with children of parents that were in receipt of welfare payments

\section{Dependent service providers treated as contenders}

The construction of children and parents highlighted in the sections above concur with many of the findings in the US however, some non-stereotypical constructions emerge in how the childcare service providers are treated in both schemes. In Ireland, there is a high reliance on small owner operators to provide services under the FPSY. It would be expected that these often locally run services would be perceived positively yet since the roll out of the FPSY a negative perception has surfaced amongst parents and providers appear to be treated as 
contenders who are not perceived to be deserving, a construction typically associated with big businesses in the US (Schneider and Ingram 1993).

This perception is evident in on-line debates in relation to the FPSY. The following quote from www.boards.ie highlights how some parents feel about service providers:

When the montessori decided to run the scheme offered by the government, they knew what they were getting in to, and now it seems like the parents are the "soft touch" as [they] want more money, to cover staff holidays (CEng 2010).

Service providers have expressed frustration and anger at being treated as contenders as demonstrated by comments from National Association of Private Childcare Providers (NPCP), an organisation that emerged organically in direct response to the introduction of the FPSY, on www.mychildcare.ie website:

Since this [FPSY] was announced the scheme has been wrought (sic) with on-going issues. The scheme was introduced with absolutely no consultation with private childcare providers which has resulted in an unviable scheme leaving many providers facing financial crisis or worse, closure. The OMCYA have chopped and changed the scheme leaving many providers angry and frustrated and parents confused and in the dark. (Smyth 2009)

Negative constructions of CCPs were reinforced by the OMCYA in a letter designed to be circulated to parents accessing either of the schemes in a community setting. Parents are urged to report CCPs 'If you qualify for either scheme but believe that your childcare service is not passing on the full subvention to you, or is charging for non-optional fees as part of an

ECCE [FPSY] place’ (OMCYA, 2010, original emphasis). Advantaged parents that access

private services that provide only the FPSY are not encouraged to 'inform' on service providers, but were given the more positive role of 'recruiting' services into the FPSY (OMCYA, 2009a).

The sense of frustration experienced by service providers is compounded by their level of financial dependence on the State and the rules of both subsidies that result in a restriction on the income they can generate. However, little momentum builds up amongst service providers to address their issues collectively. The CCPs interviewed reported that the OMCYA dealt with them individually in relation to difficulties they were experiencing with the scheme. This tactic follows an international trend in which "power is being expanded and blunted at the same time" as CCPs increasingly become involved with the provision of and

Deleted: Negative statements made about CCPs are included in letters to parents from the OMCYA that reinforces the negative construction. In a letter for parents the OMCYA states: 9 If you qualify for either scheme but believe that your childcare service is not passing on the full subvention to you, or is charging for non-optional fees as part of an ECCE [FPSY] place, you should contact your local County Childcare Committee. (OMCYA 2010 - original emphasis) Interesting, this line is included in the letter designated for parent utilising community services only. The advantaged parents are not encouraged to 'inform' on service provider but were given the more positive role of 'recruiting' services into the FPSY (OMCYA 2009a). ๆ 
contracting for services but are excluded from the decision making process "offering them responsibility without [adequate] resources and power” (Craig, Mayo et al. 2000: 329).

\section{The use of symbolic rhetoric}

A feature often associated with incentive tools such as the CCSS, is the use of 'symbolic' language that facilitates a show of great concern but relieves the State of the need to allocate resources (Schneider and Ingram, 1993). While providing a 'quality' service is a key aim of both subsidies what is evident is that the conditions of funding and amount of investment provided under the FPSY more adequately addresses the quality issue. The OMCYA stipulates that funded services must adhere to the principles of Síolta, the National Quality Framework (CECDE 2006), and Aistear, the Early Learning Framework (NCCA 2009). Minimum staff qualifications also apply and the per capita subsidy is increased by $16 \%$ where the pre-school leader holds a higher qualification (OMCYA 2009b). Historically, the FPSY was developed to replace a cash benefit that was paid to parents of all children under the age of five. While the switch to the FPSY resulted in substantial saving for the State, it needed to be mindful of withdrawing a highly visible cash benefit from parents, the majority of whom were advantaged, so the incentive for the State to design the FPSY to move beyond a verbal commitment to quality was significant.

In direct contrast the conditions of funding for the CCSS stipulate that CCPs comply only with statutory obligations that focus predominantly on child staff ratios and health and safety issues (O'Kane, 2004). Despite this, all community services in the sample have some qualified staff in place but they also rely heavily on non-qualified, part-time staff accessed through an Active Labour Market Programme, the Community Employment (CE) Scheme (O'Donoghue-Hynes and Hayes, 2011). The employment of qualified staff is a key indicator of quality (European Commission Childcare Network 2004; OECD 2006) yet eight of the ten CCPs surveyed were significantly dependent on CE staff to deliver services. Six of the services were working to a ratio of at least two CE staff for every qualified staff member while two of these services had a ratio of four CE employees to one qualified staff member. While this may have a negative impact in terms of continuity of staff and levels of training, CCPs have little other choice except to continue to rely on CE staff as they are operating in areas of 'market failure' where the need to keep costs affordable for parents is a priority. 
In 2010 the OMCYA introduced a requirement that all CCSS funded CCPs must also offer the FPSY which has by default extended the requirement to comply with national quality (CECDE 2006) and curriculum (NCCA 2009) frameworks to these services. However, it appears that only children being funded under the FPSY need to have qualified staff working with them and no such requirement extends to other children in the service. This highlights the distinction made by the State between the FPSY early education initiative, where there is requirement to have 'professional' qualified staff in place, while the CCSS childcare initiative only requires “suitable and competent adults” to work with the children (Government of Ireland 2006: 6). This demonstrates how the childcare and early education divide, that is evident in the literature of the State (Hayes 2010), has been translated in policy implementation.

\section{Concluding observations}

The CCSS appears to be a typical incentive tool designed with a negative social construction of the target parents as dependents who are 'powerless' although somewhat deserving. The use of symbolic rhetoric as a distraction is evident when the problem in relation to quality clearly requires a direct investment. This contrasts with the investment in and design of the FPSY where parents bear no costs, minimum qualifications for staff are stipulated and parents are made aware of the National Frameworks for Early Learning that service providers must comply with (OMCYA 2009a). Within both schemes children are constructed as dependent although the children of less powerful welfare recipients have little bearing in or influence on the design of the CCSS.

The service providers in both have a high level of financial dependence on the State and appear to be considered contenders who are "treated with suspicion rather than respect" (Schneider and Ingram 1997: 143). While business may be expected to "use power to pursue their own interests” (ibid) this is difficult when there is a high level of financial dependence on the State and mobilisation efforts are countered by handling queries individually.

A review of the social constructions of target populations informing the development of policy tools that realise the goals of social policy is critical because patterns emerge in which certain tools tend to be used with reliable frequency for certain groups (Pierson 2000; 
Schneider and Sidney 2009). Overall, the research seems to support findings that tools that facilitate greatest participation, voice and equitable distribution of power are frequently reserved for more 'powerful' and advantaged groups (Schneider and Ingram 1990; 1993; 1997; Schneider and Sidney 2009). As "parental decisions around childcare are a complex mixture of practical and moral concerns" (Vincent and Ball 2006: 37) the use of incentive tools is an ineffective mechanism as they address only one dimension of the decision making process, the financial implications, ignoring the need for information for parents about the role and potential benefits of ECEC as this is a relatively 'new' problem for parents in Ireland.

In Ireland the values informing ECEC policy tools are framed by a tax and welfare system that "was never intended to be redistributive and was inspired not by equality but by charity" (Kirby 2002: 27). The State is driven by a neo-liberal framework of choice and market based solutions that have produced significant inequalities within Irish society. Many of the biases that ignore the principles of social justice are perpetuated, whether deliberate or not, through the design of policy implementation tools.

Within the area of ECEC, the inequality of treatment that is evident is exacerbated by a split regime where early education and childcare are regarded and funded differently (OECD 2001; 2006). The FPSY which focuses on early education is treated more favourably in terms of rates of investment and attention to achieving quality while the lesser regarded field of childcare has a tendency to be less regulated and employ lower-trained staff. Countries with more integrated services tend to perform better in terms of provision of affordable, accessible quality ECEC services (OECD 2006). It is time that Ireland addressed this inconsistency of treatment along with the biases included in the design of our ECEC policy tools. 


\section{BIBLIOGRAPHY}

Carr, P. B. and Steele, C. M. (2009). "Stereotype threat and inflexible perseverance in problem solving." Journal of Experimental Social Psychology 45(4): 853-859.

CECDE (Centre for Early Childhood Development and Education)(2006). Siolta, the National Quality Framework for Early Childhood Education. Dublin, CECDE.

CEng (2010). Government free pre school place scheme and montessori asking for additional money. http://www.boards.ie/vbulletin/showthread.php?p=67531159

Clancy, J. (1995). Multiracial identity assertion in the sociopolitical context of primary education. The Culture of Microdiversity. N. Zack. Maryland, Rowan and Littlewood.

Craig, G., Mayo, M. and Taylor, M. (2000). "Globalization from below: implications for the Community Development Journal" Community Development Journal 35(4): 323.

European Commission Childcare Network (2004). Quality in early learning and child care services: Papers from the European Commission Childcare Network. Childcare Resource and Research Unit.

Government of Ireland (2006). Child Care (Pre-school Services) Regulations 2006. S.I. No. 505 of 2006. Dublin, Stationery Office.

Government of Ireland (2011). Government for National Recovery 2011-2016 Dublin

Hayes, N. (2010). "Childcare? Early Childhood Education and Care? Towards an integrated early years policy for young children in Ireland." Early Years 30(1): 67-78.

Kirby, P. (2002). Macroeconomic success and social vulnerability: lessons for Latin America from the Celtic Tiger, United Nations.

Milner, S. (2010). "'Choice' and 'flexibility' in reconciling work and family: towards a convergence in policy discourse on work and family in France and the UK?" Policy \& Politics 38(1): 3-21.

NCCA (National Council for Curriculum and Assessment) (2009). Aistear, the Framework for Early Learning. Dublin, NCCA.

O'Donoghue-Hynes, B. and Hayes, N. (2011). "An Evaluation of the Community Childcare Subvention Scheme using Policy Design Theory." An Leanbh Óg 4 and 5: 31-51

OECD (2001). Starting Strong Early Childhood Education and Care. Paris.

OECD (2006). Starting Strong II. Paris.

O'Kane, M. (2004). Quality and regulation in early childhood care and education. Questions of Quality International Conference Proceedings. H. Schonfeld, S. O'Brien and T. Walsh. Dublin, CECDE

OMCYA (Office of the Minister for Children and Youth Affairs)(2008). National Childcare Investment Programme (NCIP) Community Childcare Subvention Scheme (2008-2010): Fact Sheet. Dublin OMCYA.

OMCYA (2009a). Guide for Parents to free Pre-School Year in Early Childhood Care and Education (ECCE). http://www.omc.gov.ie/documents/childcare/ecce_scheme_pack/Guide_for_ Parents_to_ECCE_(english).pdf.

OMCYA (2009b). The ECCE scheme and qualifications (September 2009). http://www.omc.gov.ie/viewdocs.asp?fn=/documents/childcare/ECCE_Scheme_Pack/ECCE_ scheme_and_qualifications.doc.

OMCYA (2010). ECCE \& CCS Schemes 2010-2011 Annual Returns: If your service participates in BOTH the ECCE and CCS schemes, please see documents below: Parents letter English." http://omc.gov.ie/documents/childcare/eccecssschemesar/Batch2_Parents_Letter_Eng.pdf.

Pierson, P. (2000). "Increasing Returns, Path Dependence, and the Study of Politics." American Political Science Review 94: 251-67.

Purcal, C. and Fisher, K. (2006). "Affordability funding models for early childhood services." Australian Journal of Early Childhood 31(4): 49. 
Rigby, E., Tarrant, K. and Neuman, M. J. (2007). "Alternative Policy Designs and the Socio-political Construction of Childcare." Contemporary Issues in Early Childhood 8(2): 98-108.

Schneider, A. L. and Ingram, H. (1990). "Behavioral assumptions of policy tools." Journal of Politics 52(2): 510-529.

Schneider, A. L. and Ingram, H. (1993). "Social Construction of Target Populations: Implications for Politics and Policy." American Political Science Review 87(2): 334-347.

Schneider, A. L. and Ingram, H. (1997). Policy design for democracy, University Press of Kansas Lawrence.

Schneider, A. L. and Ingram, H. M. (2005). Introduction. Deserving and Entitled. Schneider, A. L. and Ingram, H. M. New York, SUNY: p. 1 - 34.

Schneider, A. L. and Sidney, M. (2009). "What Is Next for Policy Design and Social Construction Theory? 1." Policy Studies Journal 37(1): 103-119.

Siraj-Blatchford, I., Sylva, K., Taggart, B., Melhuish, E. and Sammons, P. (2007). The Effective Provision of Pre-school Education (EPPE) Project: Intensive case studies of practice across the English foundation stage. Vision into Practice Conference, Dublin Castle, Dublin, Centre for Early Childhood Development and Education (CECDE).

Smyth, S. (2009). Parents slow uptake on pre-school scheme adds to mounting problems with government scheme. http://www.mychildcare.ie/news26112009.asp

Soss, J. (1999). "Welfare Application Encounters." Administration \& Society 31(1): 50-94.

Steele, C. M., Spencer, S. J., and Aronson, J. (2002). "Contending with group image: The psychology of stereotype and social identity threat." Advances in experimental social psychology 34: 379-440.

Sylva, K., E. Melhuish, Sammons, P., Siraj-Blatchford, I. and Taggart, B. (2004). The Effective Provision of Pre-school Education (EPPE) project: Final Report. A longitudinal study funded by the Department of Education and Skills 1997-2004. London, EPPE Project.

Vincent, C. and Ball, S. J. (2006). Childcare, choice and class practices: middle-class parents and their children, Taylor \& Francis.

Yanow, D. (2007). "Interpretation in Policy Analysis: Analysis: On Methods and Practice." Critical Policy Analysis 1(1): 109 - 121.

European Commission (2009). Tackling Social and Cultural Inequalities through Early Childhood Education and Care in Europe. A. C. E. A. Education. Brussels, Eurydice. P9 Hantrais, L. (2004). Responding to family change in Europe. Bristol, The Policy Press. Heckman, J. J. and D. V. Masterov (2007). "The productivity argument for investing in young children." Applied Economic Perspectives and Policy 29(3): 446.

Ingram, H. M. and S. R. Smith (1993). Public policy for democracy, Brookings Institution.

James, A. and A. Prout (1997). Constructing and reconstructing childhood: Contemporary issues in the sociological study of childhood. London, Falmer Press.

Whitley, R. D. (1991). "The social construction of business systems in East Asia." Organization Studies 12(1): 1.

Formatted: Font: Bold

Formatted: Underline

Formatted: Underline

Formatted: Font: Bold

Formatted: Underline

Formatted: Underline

Formatted: Underline

Formatted: Font: Bold

Formatted: Indent: Left: 0

pt, Hanging: 36 pt, Space

After: 0 pt, Line spacing:

single 
'Interviews with ten community childcare provider (CCP) managers across Dublin City' and the administration of questionnaires to sixty two parents using these services took place in April 2009. Ten CCPs represents approximately $10 \%$ of providers in the Dublin City area and $1 \%$ of CSPs nationally. 